\title{
Problem-based learning (PBL): tutor perception of group work and learning
}

\section{Zoltán Szabó, Márta Harangi, Eva Nylander, Annette Theodorsson and Bo Davidson}

\author{
Corresponding author: Zoltán Szabó Zoltan.Szabo@lio.se \\ Department: Dept. of Cardiothoracic Anesthesia, Heart \& Medicine Center, County Council of \\ Östergötland, S-581 85 Linköping, Sweden.
}

Received: 09/12/2014

Accepted: 16/12/2014

Published: 31/12/2014

\begin{abstract}
Introduction: This paper reports a survey on how PBL is perceived by tutors. A questionnaire including 45 questions answered on a Likert-type scale, and an open question was constructed. The aim was to identify factors that tutors believe promote or impede student learning. All faculty tutors (116) teaching five different student semester cohorts at our medical college during the Spring Term of 2013 were included. Seventy-four tutors responded (64\%).
\end{abstract}

Methods: Descriptive statistics, explorative factor analysis.

Results: Factor analysis identified five factors which explained $52 \%$ of the variation. These factors were: PBL as a pedagogic method; tutoring problem analysis in the group; barriers to student learning; the tutor's role in the group; and the relationship between theory and practice. The model as a whole showed high reliability (Chrombach's alpha $=0,81$ ). When responding to the open question, the tutors suggested organizational changes, improvement in tutor competence, clear goals in the curriculum, and smaller tutorial groups/miscellaneous.

Conclusions: The tutors' approach adhered to classical PBL methodology, and they considered it to be a good instrument for student learning. The tutorial group was seen as promoting learning. Problems related to group dynamics and tutor competence were considered a hindrance to learning.

Keywords: Problem-based learning, group work, tutor, competence, self-directed learning.

\section{Article}

\section{Introduction}

A PBL (problem based learning) medical program was started in 1986 at the Linköping Medical College and was among the first in Europe. This method was intended to be flexible and appropriate in several academic environments (Dahlgren, Hult, Dahlgren, Hård Af Segerstad, \& Johansson, 2006). "In a post PBL era" Tarnvik (2007) criticizes PBL because of ineffective learning in dysfunctional groups resulting from quiet and/or dominating students, and non-attendance (Tarnvik, 2007). 
Szabó Z, Harangi M, Nylander E, Theodorsson A and Davidson B. MedEdPublish 2014, 3: 46

http://dx.doi.org/10.15694/mep.2014.003.0046

In a global society, however, the need for knowledge and the way students learn may both change rapidly.

A pilot survey ( $\mathrm{N}=113$ ) conducted in 2011, on how our students experienced PBL, showed that both group work and tutoring needed to be improved(Harangi, 2012).

The last curriculum change was made in 2004 and another one is planned in the near future. Based on the pilot study (Harangi, 2012) and before the coming curriculum change is made, a teacher -initiated survey including all students and tutors at the Medical College was carried out during the Spring Term 2013. In order to facilitate improvements in the program, we performed this survey at the same time in order to obtain a better understanding of how tutors perceive student learning in tutorial groups. We aim to repeat this survey two years after the next change in curriculum in order to detect weaknesses and explore possible causes.

\section{Method}

All tutors involved in the medical program during the Spring Term of 2013 were included in this survey. The study was approved by the Regional Ethical Review Board in Linköping, Sweden (Dnr. 2012/298-31). A short information sheet was distributed prior to this anonymous survey. The number of completed questionnaires for each of the five curriculum terms was noted. Participation was voluntary assuring the confidentiality of the study. Curriculum Terms 1-5 of Linköping University's medical program have supervised tutorial groups. From Term 6 students conduct their own group studies without tutorial help. The Swedish language without negations was used in the survey. The Likert-type scale we used had four points: $\mathbf{1}$ totally disagree; $\mathbf{2}$ tend to disagree; $\mathbf{3}$ tend to agree; $\mathbf{4}$ totally agree. The fifth alternative $\mathbf{5}$ don't know/not applicable, did not have a Likert function and was considered lost data.

Our 45 structured questions were grouped as follows: PBL as a method (12 questions); group work (7 questions); role of the tutor (19 questions); factors stimulating/impeding student learning (12 questions); and comparison of traditional and PBL curriculae (1 question). In addition, the survey had one open question; "Do you have any ideas or proposals on how to improve PBL and tutorial group activity in the medical program?". Each term administrator distributed the questionnaires at the first tutor meeting of the Spring Term 2013. The tutors could either answer the questions immediately after the meeting or send in the completed questionnaire within two weeks. A single e-mail reminder was sent after three weeks.

A total of 116 questionnaires were distributed. The questionnaire answers were entered into a database by two persons who checked each other in order to reduce errors. One in ten data entries were controlled by a third person after completion of the database.

SPSS (IBM SPSS statistic standard 20. 2012, USA) was used for statistics analysis. The results are presented as mean $\pm \mathrm{SD}$. Descriptive statistics and factor analysis were performed.

We used a standard variant of explorative factor analysis with Kaiser`s criterion and Varimax rotation to get a simpler factor structure. Factor loadings were set at 0,50 (Kline, 1994). An index variable for each factor and means for all five factors were calculated. Reliability of the factors was checked separately using Chrombach's alpha with a limit of reliability set at 0,60 .

\section{Results}

Seventy-four of 116 tutors completed the questionnaire (64\%). External loss of data was 37\% (43 cases). Internal loss of data was $3.1 \%$ (109 of 3285 answers were missing). The number of tutors responding for each Curriculum Term (T) were: T1, 23; T2, 17; T3, 12; T4, 10; T5, 12. Nineteen of the tutors $(26 \%)$ answered the open question.

Answers to the structured questions 
Szabó Z, Harangi M, Nylander E, Theodorsson A and Davidson B. MedEdPublish 2014, 3: 46 http://dx.doi.org/10.15694/mep.2014.003.0046

Five factors (see Tables 1-5) were found to explain $52 \%$ of the total variance.

The reliability of the model was tested by Chrombach's alpha (0,60 cut off) for the model as a whole and also for the five factors separately as shown in Table 6. Answers to the descriptive questions regarding factors that, in the tutor's opinion, promote and impede student learning are presented here as mean \pm SD in Tables 7 and 8 , respectively. The Likert scores of the negatively formulated questions presented in Table 8 were recoded and inverted so that high scores became low and vice versa to accentuate the negative impact of the factor.

\section{Answers to the open question}

The responses describe the tutors' suggestions for improvement of PBL and group work in our medical program. The answers are presented in the form of citations and sorted into four dominant themes: organizational aspects of PBL; tutor competence as regards both PBL and subject; learning goals; size of tutorial groups; and lastly other comments. The comments are translated as exactly as possible from Swedish, and the text is written in italic form with quotation marks. The answers were placed in the following groups according to content:

-Organizational aspects:

- "It's a shame that the students cannot access LISA (The County Councils intranet). There are very good promemoria such as breast and colon cancer processes, routines etc. providing support and information for the physician. This increases the student's understanding that there are treatment programs with more to follow."

-" Greater freedom in booking tutorial times., There should be more time in the beginning of the term where we can reflect on why we do what we do. The tutor is a resource to be used - not a controller as he/she has become. We need to think about the layout; what it is that motivates the students here and now - not in which order we think they should learn. "

-" Longer tutorial time ( 3 hours), only once a week if necessary, enabling more extensive case discussions This would lead to a better combination of depth and breadth of learning and give more time for discussion (and perhaps make it easier to find enough tutors) "

- "Less teaching should be done using PBL"

-" In my opinion PBL is an inadequate learning tool for the first 4 curriculum semesters. Students do not have the basic knowledge required for "problem solving". It is hard enough to comprehend the problem at all. It is not reasonable to expect $T 2$ students to cover circulatory, respiratory and neurophysiology in one term in a satisfactory manner."

- "Sometimes I wonder how time-efficient it is with one teacher per 8 students for 2 hours. At the same time, I certainly do not think that the tutorial group should be replaced by something else. Perhaps the tutor need not be present all the time. "

-"Work for clear feedback on performance, not only tutorial group work"

Tutor competence as regards both PBL andsubject:

Some tutors pointed out that both teaching skills in PBL methodology and subject knowledge related to actual cases is important during tutorial sessions. There are two distinct features in the tutors' proposals; several want subject-qualified tutors while others comment on the selection of tutors.

-" Subject-competent PBL tutors “

-" Expert tutors and several tutors / term depending on area of expertise"

-" Subject-competent tutors i.e. a tutor in each specific field rather from another that may direct discussion towards their own field" 
Szabó Z, Harangi M, Nylander E, Theodorsson A and Davidson B. MedEdPublish 2014, 3: 46

http://dx.doi.org/10.15694/mep.2014.003.0046

-"Needed : planned structured tutor

education at a higher level than today with tutor certification .

Being a tutor must have status and be appreciated"

-Clearer objectives in the curriculum:

Some argued that the medical curriculum should have clear objectives pointing out that more detailed description of goals would provide students with support in their learning.

-" Clearer, more detailed learning objectives, and tutor guides"

-"Better description of goals = more detailed"

-"The goals expressed in the so-called pyramids are perceived as difficult.

Clear goals lead to a greater sense of security for students "

Tutorial group size:

Several tutors suggested smaller tutorial groups.

-" Groups should not include more than the 8 student round "pain limit"

-"Maximum 6 students/tutorial group"

-" Somewhat smaller groups 5 - 6, then it is easier for everyone to have their say and less easy to avoid contributing to the discussion"

Other comments:

There were also other suggestions for the improvement of teaching.

-"Dare to rely on solid patient cases, demand a more varied approach from the students. Continually emphasize HEL1 (integrated and patient centered perspective) from the doctor's role perspective. Let the tutor reflect on the case (after the group activity)."

-"Sometimes it seems a lot for the students to read before a group activity, while at other times it is less. It is difficult for them to know when the cases are large."

-"Increased demands on the student, it is not good enough to only look at Wikipedia or only read the basics"

-"I feel I have much to offer students, both to inspire calm and explain to them what is it like to be a student in a medical program. More dedicated and recently graduated young doctors may be preferable for as tutors in $T 1 "$.

Summarizing the answers to the open question:

-Tutors experienced problem-based learning as a great tool for students studying medicine.

-Tutors felt they had a positive effect on student learning.

-Tutors believed PBL to be an adequate method to bring together theory and clinical praxis in medical education.

- Student learning in a group is promoted through interaction and through the tutor's facilitating and supportive function.

-The tutors identified elements in PBL methodology that impede learning: 
Szabó Z, Harangi M, Nylander E, Theodorsson A and Davidson B. MedEdPublish 2014, 3: 46

http://dx.doi.org/10.15694/mep.2014.003.0046

-Sense of inadequacy, stress due to lack of time.

-Sluggish discussion in the group.

-Group work is perceived by the students as an examination.

-Too large PBL groups and incompetent tutors. Tutor not acting in concordance with PBL methodology, problems in group dynamics, or tutor shifting to more traditional teaching methods.

Based on answers to the open question, the tutors made suggestions in the following areas:

1. Organization.

2. Subject-competent tutors.

3. Clearer description of goals.

4. Fewer students in the group.

\section{DISCUSSION}

The main finding in this descriptive study was that tutors at our Medical College in Linköping generally consider PBL to be an adequate tool for medical education. However, they also point out weaknesses in the system and made several suggestions to improve/stimulate learning. The tutors who answered the open question suggested the following: clearer curriculum objectives; subject-competent tutors; and smaller tutorial groups. An improvement in the organization is also required.

According to Bryman, there are three main criteria in social science research; the study's reliability, validity and replicability (Bryman, 2002). He argues that reliability is about stability, i.e. if the study is repeated, and you measure the same variables under similar circumstances, you will get approximately the same results (Bryman, 2002). Reliability in this survey is also about how the survey was designed and the statistics performed.

The questionnaire was constructed with four possible response options and a fifth that did not have a Likert function and was recoded as internal loss of data. The response option " 5 " was used to give the respondent the opportunity to avoid taking a position based on the four-point Likert-scale.

The questionnaire was structured and standardized according to Trost and Patel \& Davidson (Patel, 2003; Trost, 2007) who argue that a quantitative survey using a Likert scale should consist of at least 40-50 questions (the present survey comprised 45 questions). A problem pointed out by Trost is that surveys that use a Likert scale lead to respondents filling in the questionnaire automatically with a negative impact on reliability (Trost, 2007). We did not use emotionally charged words, in line with Bryman's recommendations, to enhance reliability (Bryman, 2002).

Tutors are the key figures in a successful problem-based teaching as Mc Allister et al showed in their study(McAllister et al., 2014). In line with Medical education guide 15 for PBL the first requirement to be a tutor is: "a subject-matter expert who understands the course and curriculum and who has the appropriate group facilitation skills" and the second requirement is a medically qualified person who is not an expert in the subject but possess group supervision skills (Davis, 1999). This was described by Davis already in 1999, and this is in accordance with the opinions of the tutors at our Medical College (Davis, 1999). Even later, in 2002, Dolmans et al pointed out that "how to deal with subject matter expertise" was as important as improving the learning process (Diana H.J.M. Dolmans, 2002). This is reflected in the results of our study where tutors want to see subject-competent tutors leading tutorial groups.

The opinions of tutors in our medical program where the PBL has been used for more than twenty years differed from those described by Kaufman, of tutors at the start of a PBL curriculum(Kaufman \& Holmes, 1996). One thing common to both our and Kaufman's study is that tutors favor the PBL method (Kaufman \& 
Szabó Z, Harangi M, Nylander E, Theodorsson A and Davidson B. MedEdPublish 2014, 3: 46

http://dx.doi.org/10.15694/mep.2014.003.0046

Holmes, 1996). Kaufman's study was centered on tutors as a group while our study centers around tutors' views on student learning.

The tutors in our study have the same attitude as Dahlgren described in 1998, that tutors perceive the tutorial process in the PBL tutorial group in the same way as they do at the post-graduate level (Dahlgren, Castensson, \& Dahlgren, 1998).

In conclusion: the tutor's approach to group work and learning was in concordance with the classical description of PBL, since they considered it a good instrument for student learning. Group work was seen as promoting student learning. The tutors identified group dynamics and tutors' role and competence as problems hindering student learning.

The tutors responding to the open question made suggestions of organizational nature to improve student learning, proposing subject-competent tutors, clearer goals in the curriculum, and smaller tutorial groups.

\author{
Authors \\ Zoltán Szabó MD., $\mathrm{PhD}^{1}$, Márta Harangi $\mathrm{MSS}^{2}$, Eva Nylander MD., $\mathrm{PhD}^{3}$ Annette Theodorsson MD., PhD , \\ Bo Davidson $\mathrm{PhD}^{5}$. \\ ${ }^{1}$ Division of Cardiovascular Medicine, Department of Medical and Health Sciences, Faculty of Health \\ Sciences, Linköping University, Department of Thoracic and Vascular Surgery, Heart and Medicine Center, \\ County Council of Östergötland ${ }^{2}$ Linköping, Sweden, ${ }^{3}$ Department of Clinical Physiology and Department of \\ Medical and Health Sciences, Linköping University, ${ }^{4}$ Neurosurgery, Department of Clinical and \\ Experimental Medicine, Faculty of Health Sciences, Linköping University, Department of Neurosurgery, \\ County Council of Östergötland, Linköping, Sweden, ${ }^{5}$ Department of Behavioral Sciences and Learning, \\ Linköping University, Linköping, Sweden.
}

\title{
Acknowledgement
}

We thank Mr. Olof Malm for helping with registration of data in the database in an exemplary fashion.

The study was initiated by teachers in the "Network for university teachers at the medical college in Linköping" in collaboration with other teachers from the medical program and the IBL institution of Linköping University. It was funded by Linköping University. We thank the program director for her support in distributing the surveys.

\section{Declaration of Interest}

The authors report no declaration of interest. 
Szabó Z, Harangi M, Nylander E, Theodorsson A and Davidson B. MedEdPublish 2014, 3: 46

http://dx.doi.org/10.15694/mep.2014.003.0046

\section{Practice points}

- This was a survey of all 116 tutors at the Medical College, University of Linköping, to examine their perception of factors promoting and impeding learning in tutorial groups (Tutorials are held curriculum terms 1-5). A questionnaire comprising 45 questions with Likert scores was used, together with an open question.

- Explorative factor analysis has identified five factors explaining $52 \%$ of the variation. These factors were: PBL as a pedagogic method; tutoring problem analysis in groups; barriers to student learning; the tutor's role in the group; and the relationship between theory and practice. The model had a high reliability as Chrombach's alpha was 0,81 .

- Almost thirty per cent of the tutors responded to the open question. They suggested organizational changes, improvement of tutor competence, clear goals in the curriculum and smaller tutorial groups.

- The tutors considered the classical PBL method as a good instrument for student learning. The tutorial group was also perceived as promoting learning. Problems related to group dynamics and tutor role and competence were considered a hindrance to learning.

- Organizational changes, subject-competent tutors, clearer goals in the curriculum, and smaller tutorial groups were suggestions to improve learning. This must be interpreted with caution as the response frequency to the open question was only $26 \%$ and the above-named proposals cannot therefore be generalized. 
Szabó Z, Harangi M, Nylander E, Theodorsson A and Davidson B. MedEdPublish 2014, 3: 46

http://dx.doi.org/10.15694/mep.2014.003.0046

\section{References}

Bryman, A. (2002). Samhällsvetenskapliga metoder: Lieber.

Dahlgren, M. A., Castensson, R., \& Dahlgren, L. O. (1998). PBL from the teachers' perspective: Conceptions of the tutor's role within problem based learning. Higher Education, 36(4), 437-447. http://dx.doi.org/10.1023/A:1003467910288

Dahlgren, M. A., Hult, H., Dahlgren, L. O., Hård Af Segerstad, H., \& Johansson, K. (2006). From senior student to novice worker: Learning trajectories in political science, psychology and mechanical engineering. Studies in Higher Education, 31(5), 569-586.

http://dx.doi.org/10.1080/03075070600923400

Davis, M. H. (1999). AMEE Medical Education Guide No. 15: Problem-based learning: a practical guide. Med Teach, 21(2), 130-140. doi: 10.1080/01421599979743

http://dx.doi.org/10.1080/01421599979743

Diana H.J.M. Dolmans, W. H. G., Jos H.C. Moust, Willem S. Ed Grave, Ineke H:A:P: Wolfhagen, Cees P.M. Van Der Vleuten. (2002). Trends in research on the tutor in problem based learning: conclusions and implications for educational practice and research. Medical Thecher, 24(2), 173180. http://dx.doi.org/10.1080/01421590220125277

Harangi, M. (2012). from http://www.divaportal.org/smash/searchref.jsf?pid=diva2:496283\&searchId=1\&rvn=5

Kaufman, D. M., \& Holmes, D. B. (1996). Tutoring in problem-based learning: perceptions of teachers and students. Med Educ, 30(5), 371-377.

http://dx.doi.org/10.1111/j.1365-2923.1996.tb00850.x

Kline, P. (1994). An easy guide to factor analysis Routledge.

McAllister, A., Aanstoot, J., Hammarström, I. L., Samuelsson, C., Johannesson, E., Sandström, K., \& Berglind, U. (2014). Learning in the tutorial group: A balance between individual freedom and institutional control. Clinical Linguistics and Phonetics, 28(1-2), 47-59.

http://dx.doi.org/10.3109/02699206.2013.809148

http://dx.doi.org/10.3109/02699206.2013.809148

Patel, R., Davidsson, B. (2003). Forskningsmetodikens Grunder: att planera, genomföra och rapportera en undersökning. Lund: Studentlitteratur.

Tarnvik, A. (2007). Revival of the case method: a way to retain student-centred learning in a postPBL era. Med Teach, 29(1), e32-36. doi: 10.1080/01421590601039968

http://dx.doi.org/10.1080/01421590601039968

Trost, J. (2007). Enkätboken. Lund: Studentlitteratur. 
Szabó Z, Harangi M, Nylander E, Theodorsson A and Davidson B. MedEdPublish 2014, 3: 46

http://dx.doi.org/10.15694/mep.2014.003.0046

\section{Table legend}

Table 1. Factor one: Tutors' experience regarding PBL as pedagogic method. Index variable: PBL as pedagogic method = 3.01; M=Mean; $\mathrm{S}=$ standard deviation SD.

Table 2. Factor 2: Tutors' experience of supervision of problem processing in the tutorial group. Index variable: Supervision of problem processing in the tutorial group = 3,36; $M=$ Mean; $S=S D$

Table 3. Factor 3: Tutors' perception of potential barriers to student learning in PBL. Index Variable: Potential barriers to student learning in $\mathrm{PBL}=1.80 ; \mathrm{M}=$ mean; $\mathrm{S}=\mathrm{SD}$

Table 4. Factor 4: Tutors' experienceof their own role in tutorial groups.

Index Variable: The tutor's role in the tutorial group $=2.50$

Table 5. Factor 5: Tutors' perception of the relationship between theory and practice in PBL. Index Variable: Relationship between theory and practice in $\mathrm{PBL}=3.09 ; \mathrm{M}=$ mean; $\mathrm{S}=\mathrm{SD}$

Table 6. The results of the five factors' $(n=5)$ reliability using the homogeneity measure Cronbach `s Alpha.

Table 7. Conditions considered by the tutors to be promoters of learning in group work. The averages are presented in descending order. $\mathrm{M}=$ mean; $\mathrm{S}=\mathrm{SD}$

Table 8. Factors impeding learning in the tutorial group. $M=$ mean; $S=S D$. The averages are presented in ascending order. For the negatively correlated items in this factor, the Likert scores were recoded and inverted to accentuate the negative impact.

\section{Table 1.}

\section{PBL as pedagogical method}

PBL helps the student acquire relevant knowledge for their profession

PBL contributes to the independence of students

Group tutorials help students to evaluate their own knowledge

Group tutorials enrich student learning (communication and reflection)

Group tutorials help students share experiences with each other

In group tutorials the students have time to sort out issues that are hard to understand

Group discussions help problem processing

Work in tutorial group helps students to reache an optimal depth of knowledge

In my opinion, PBL is a great tool for student learning

M S

$3,43 \quad, 667$

3,62 ,591

3,32 ,696

$\mathbf{3 , 5 4}, \mathbf{5 7 8}$

3,68 ,498

3,13 ,769

$\mathbf{3 , 5 9}, \mathbf{5 7 5}$

$2,86 \quad, 698$

$3,58 \quad, 622$ 
Szabó Z, Harangi M, Nylander E, Theodorsson A and Davidson B. MedEdPublish 2014, 3: 46

http://dx.doi.org/10.15694/mep.2014.003.0046

Table 2.

\section{Supervising problem processing in tutorial groups}

I support student learning by helping them to achieve the learning goals

I help the students to fulfil the aims of the course

I function as a resource person in the group

I participate in creating a positive work environment for the group

I encourage student learning by stimulating questions

I stress the importance of constant student reflection

I see to it that all students in the group have their say

I am sensitive to the wishes of the students regarding their need for support

I am interested in being a tutor

\begin{tabular}{cc}
$\mathbf{M}$ & $\mathbf{S}$ \\
$\mathbf{3 , 5 4}$ & $\mathbf{, 6 2 7}$ \\
$\mathbf{3 , 5 0}$ & $\mathbf{, 6 0 5}$ \\
$\mathbf{3 , 0 1}$ & $\mathbf{, 8 5 7}$ \\
$\mathbf{3 , 6 7}$ & $\mathbf{, 5 0 1}$ \\
$\mathbf{3 , 3 1}$ & $\mathbf{, 7 1 3}$ \\
$\mathbf{2 , 9 7}$ & $\mathbf{, 8 1 0}$ \\
\hline $\mathbf{3 , 5 1}$ & $\mathbf{, 6 4 9}$ \\
\hline $\mathbf{3 , 5 0}$ & $\mathbf{, 6 0 7}$ \\
\hline $\mathbf{3 , 2 4}$ & $\mathbf{, 9 0 9}$ \\
\hline
\end{tabular}

Table 3.

\begin{tabular}{lll}
\hline Potential barriers to student learning in PBL & $\mathbf{M}$ & $\mathbf{S}$ \\
I have relevant teaching qualifications in PBL & $\mathbf{3 , 3 7}$ & $\mathbf{8 6 2}$ \\
It is difficult for students to know if they have learned enough & $\mathbf{3 , 2 5}$ & $\mathbf{, 6 7 0}$ \\
Discussions in the tutorial group are sluggish & $\mathbf{1 , 8 2}$ & $\mathbf{, 7 7 9}$ \\
Work in the tutorial group has a test function and is stressful for students & $\mathbf{1 , 7 2}$ & $\mathbf{, 7 0 9}$ \\
Time for discussion in the tutorial group is too short & $\mathbf{2 , 0 7}$ & $\mathbf{7 1 3}$ \\
The group size is just right from a tutorial point of view & $\mathbf{3 , 5 1}$ & $\mathbf{, 7 3 1}$ \\
Discussion in the tutorial group creates uncertainty among students & $\mathbf{2 , 2 7}$ & $\mathbf{, 8 0 0}$ \\
PBL evokes feelings of inadequacy in students & $\mathbf{2 , 2 6}$ & $\mathbf{8 3 4}$
\end{tabular}

Table 4.

\begin{tabular}{lll}
\hline The tutor's role in the tutorial group & $\mathbf{M}$ & $\mathbf{S}$ \\
Students need my feedback to support their learning & $\mathbf{3 , 0 5}$ & $\mathbf{, 7 7 2}$ \\
I tend to explain and teach the tutorial group & $\mathbf{2 , 1 6}$ & $\mathbf{8 6 1}$ \\
My role as tutor is usually passive in the tutorial group & $\mathbf{2 , 7 1}$ & $\mathbf{8 3 6}$ \\
The students find it difficult to judge the relevance of literature found & $\mathbf{2 , 6 0}$ & $\mathbf{, 7 9 4}$ \\
\hline
\end{tabular}


Szabó Z, Harangi M, Nylander E, Theodorsson A and Davidson B. MedEdPublish 2014, 3: 46

http://dx.doi.org/10.15694/mep.2014.003.0046

\section{Table 5.}

\section{Relationship between theory and practice in PBL}

M S

PBL motivates me to continuously update my skills as a teacher

PBL is based on true-life cases which creates involvement

Table 6.

\begin{tabular}{ll}
\hline Factor & Cronbach`s Alpha \\
1. PBL as pedagogic method & $\mathbf{, 8 5 5}$ \\
2. Tutoring problem processing in tutorial groups & $\mathbf{, 8 5 4}$ \\
3. Potential barriers to student learning in PBL & $\mathbf{, 7 6 6}$ \\
4. The tutor's role in the tutorial group & $\mathbf{, 5 5 4}$ \\
5. Relationship between theory and practice in PBL & $\mathbf{, 5 7 2}$ \\
Statements throughout the questionnaires & $\mathbf{8 1 0}$ \\
\hline
\end{tabular}

Table 7.

\begin{tabular}{lll}
\hline Assertions & $\mathbf{M}$ & $\mathbf{S}$ \\
The students' motivation level affects work in the tutorial group & $\mathbf{3 , 8 1}$ & $\mathbf{, 5 1 5}$ \\
PBL stimulates student learning & $\mathbf{3 , 7 1}$ & $\mathbf{5 3 9}$ \\
Tutorial groups help students to share experiences with each other & $\mathbf{3 , 6 8}$ & $\mathbf{, 4 9 8}$ \\
I try to create a positive working atmosphere in the tutorial group & $\mathbf{3 , 6 7}$ & $\mathbf{, 5 0 1}$ \\
PBL contributes to the independence of students Group discussion facilitates problem & $\mathbf{3 , 6 2}$ & $\mathbf{5 9 1}$ \\
processing & $\mathbf{3 , 5 9}$ & $\mathbf{5 7 5}$ \\
I intervene and redirect discussion if it takes a wrong turn & $\mathbf{3 , 5 4}$ & $\mathbf{, 6 4 8}$ \\
Group meetings enrich student learning through communication & $\mathbf{3 , 5 4}$ & $\mathbf{5 7 8}$ \\
I support learning by helping students perform the learning tasks & $\mathbf{3 , 5 4}$ & $\mathbf{, 6 2 7}$ \\
I see to it that all students have their say in the group & $\mathbf{3 , 5 1}$ & $\mathbf{6 4 9}$ \\
Tutorial group size is right from a tutorial point of view & $\mathbf{3 , 5 1}$ & $\mathbf{, 7 3 1}$ \\
I help the students to achieve the objectives of the course & $\mathbf{3 , 5 0}$ & $\mathbf{, 6 0 5}$ \\
I am sensitive to the wishes of students when they need support & $\mathbf{3 , 5 0}$ & $\mathbf{, 6 0 7}$ \\
\hline
\end{tabular}

Table 8.

\begin{tabular}{lll}
\hline Assertions & M & S \\
I often have problems with group dynamics in the tutorial group & $\mathbf{1 , 5 6}$ & $\mathbf{, 6 7 0}$ \\
Work in the group has a test function and is stressful for students & $\mathbf{1 , 7 2}$ & $\mathbf{, 7 0 9}$ \\
Discussions in the tutorial group are sluggish & $\mathbf{1 , 8 2}$ & $\mathbf{, 7 7 9}$ \\
Time for tutorial group work is too short & $\mathbf{2 , 0 7}$ & $\mathbf{, 8 6 7}$ \\
I tend to explain and teach the group & $\mathbf{2 , 1 6}$ & $\mathbf{, 8 6 1}$ \\
\hline
\end{tabular}

